\title{
A INVISIBILIZAÇÃO DAS CRISES: DO COLAPSO CLIMÁTICO À PANDEMIA DA COVID-19
}

Kathy de Freitas Marinho dos Reis ${ }^{1}$

Ronaldo Eustáquio Feitoza Senra²

Resumo: Na necessidade de visibilização das crises, esta pesquisa se constrói. Este artigo faz parte da pesquisa intitulada "O Anti-intelectualismo e a Educação Ambiental: Implicações ao debate da Crise Climática", do Mestrado em Ensino, PPGen/IFMT, inserida na Rede de Educação Ambiental e Justiça Climática REAJA e no Grupo de Estudos em Educação Ambiental e Educação Campesina - GEAC. Com o objetivo de revelar o fenômeno anti-intelectual como instrumento político e seus impactos nocivos a questão climática, cinco educadores ambientalistas contribuíram para a construção da dissertação. $O$ aporte metodológico é o Materialismo Histórico-dialético. Dar visibilidade às Crises é resistir a seu causador, o sistema econômico estabelecido.

Palavras-chave: Visibilização; Crise Climática; Crise Pandêmica.

Abstract: In the need to make crises visible, this research is built. This article is part of the research entitled: "Anti-intellectualism and Environmental Education: Implications for the debate on the Climate Crisis", from the Master in Education, PPGen / IFMT, inserted in the Environmental Education and Climate Justice Network - REAJA and in the Study Group in Environmental Education and Rural Education - GEAC. To reveal the anti-intellectual phenomenon as a political instrument and its harmful impacts on the climate issue, five environmental educators contributed to the construction of the dissertation. The methodological contribution is Dialectical Historical Materialism. To give visibility to Crises is to resist their originator, the established economic system.

Keywords: Visibility; Climate Crisis; Pandemic Crisis.

\footnotetext{
${ }^{1}$ Instituto Federal de Educação, Ciência e Tecnologia do Estado de Mato Grosso - IFMT. E-mail: kathym.reis27@gmail.com, Lattes: http://lattes.cnpq.br/9628620770385607

2 Instituto Federal de Educação, Ciência e Tecnologia do Estado de Mato Grosso - IFMT.

E-mail: bolinhasenra@yahoo.com.br, Lattes: http://lattes.cnpq.br/9139475718201089
} 


\section{Introdução}

Compreendendo a importância da discussão acerca de questões ambientais, a pesquisa objetiva descrever e interpretar os impactos do pensamento anti-intelectual na Educação Ambiental, especialmente no que implica a Crise Climática, sendo a denúncia um caminho para alterações da realidade. A intencionalidade foi desvelar o fenômeno anti-intelectual como prejudicial, como instrumento de manipulação política, que mascara e invisibiliza as discussões sociais, políticas e econômicas, que envolvem diretamente a luta de classes e a manutenção do sistema econômico, impedindo um aprofundamento na causa da degradação ambiental, o capitalismo. Um vídeo Documentário ${ }^{3}$ foi produzido como parte do resultado da pesquisa, evidenciando a resistência dos entrevistados, frente aos ataques à Educação Ambiental.

A crise climática é uma realidade já há muito tempo denunciada por cientistas que reconhecem a importância de dar visibilidade às questões ambientais, pretendendo não somente a criação de uma sociedade mais sustentável, mas evidenciando a realidade de extinção de toda forma de vida. A denúncia da invisibilização da Crise Climática e sanitária é realizada, neste artigo, com o auxílio do livro II da República de Platão e, especificamente, é utilizado o mito do "Anel de Giges", enfatizando a importância da justiça, nas concepções de meios e fins, no que tange aos temas abordados, buscando associar as experiências no campo político brasileiro - que se referem às crises citadas nesta pesquisa - aos ensinamentos do filósofo Platão, datado a dois mil e trezentos anos atrás.

A realidade atual é de Colapso Climático, ou seja, não existe outra forma de reverter esse quadro, senão alterando a forma humana de produção da vida material. É emergente a necessidade de transformação do padrão desenfreado de consumo, tratando a natureza como uma produtora de matéria prima infinita. Esta discussão se faz revelando a causa motriz da Crise Climática, exigindo uma práxis que altere o sistema e não o Clima, como afirma a REAJA ${ }^{4}$. Na alteração desse sistema, também é importante desvelar as questões do negacionismo climático.

\footnotetext{
${ }^{3}$ Vídeo produzido a partir dos resultados obtidos através da pesquisa intitulada: O Anti-intelectualismo e Educação Ambiental: implicações ao debate da crise Climática. Pesquisa aprovada pelo edital 46/2019. PROPES/IFMT. 2020. O vídeo intitulado: Anti-intelectualismo e Educação Ambiental: Kathy Reis. Disponível em: <https://www.youtube.com/watch?v=dFpLEkfqQAg>. Acesso em 25 ago. 2020.

${ }^{4}$ No ano de 2016, a Fapemat lança um edital induzido para redes internacionais (037/2016/Fapemat) o que possibilita a aprovação da atual "Rede Internacional de Pesquisadores em Justiça Climática e Educação Ambiental (REAJA)", que possui características do projeto do CNPq, mas ampliada nos cenários nacionais e internacionais. No ano de 2019, a Fapemat concedeu a prorrogação do projeto até o ano de 2020 (processo no. 0602434/2016), devidamente registrado na UFMT [Propeq cadastro: 139/2018]. Atualmente, cinco países fortalecem a REAJA: Brasil, México, Cuba, Espanha e Portugal. No Brasil, envolve 7 estados de 3 regiões brasileiras. Com a maciça presença de 12 universidades, a REAJA conta também com as organizações não governamentais e uma entidade governamental, no total de 16 entidades. Blog: Grupo Pesquisador em Educação Ambiental, Comunicação e Arte - GPEA. Disponível em: <https://gpeaufmt.blogspot.com/p/reaja 31.html>. Acesso em 25 ago. 2020.
} 
Na retórica desenvolvimentista, o modelo capitalista de produção procurou invisibilizar as pesquisas que divergem de sua lógica de exploração e predação. Crise Climática é uma delas, enquanto houve argumentos, a discussão tornouse invisibilizada, até que impactos concretos passaram a revelar a fragilidade do modelo capitalista. A pandemia por Coronavírus revelou que o freio do dito "progresso" pode ser acionado e, mesmo diante de discursos de negação da crise sanitária, as evidências da pandemia forçaram algumas das grandes potências econômicas a reduzirem a produção temporariamente, prescrevendo a possibilidade de sua alteração. Dar visibilidade às crises, é parte desse processo de transformação.

\section{O anel de Giges: a invisibilização das crises}

"Os fins não justificam os meios."

Platão

O livro II da República de Platão relata o diálogo entre o filósofo Sócrates e dois de seus amigos, Glauco e Adimanto, os quais, em um embate de ideias, tratavam da questão da justiça e injustiça. Depois de todos discorrerem sobre tais questões, Adimanto sugeriu uma alegoria para melhor compreensão do tema tratado: "ser justo quando ninguém pode te ver". Assim, o anel de Giges foi o mito utilizado. A alegoria narra a história de um humilde pastor de ovelhas que pastoreava durante uma tempestade e, em meio à turbulência, sentiu um grande tremor de terra. No mesmo instante, o solo se abriu em uma fenda e, lá dentro, o pastor avistou um cavalo de bronze, e no interior dele se encontrava um homem morto, em cujo dedo brilhava um anel de ouro, que o pastor pegou e foi embora.

No outro dia, foi a uma assembleia que reuniu todos os pastores da região; estes preparavam um registro sobre o rebanho para entregar ao rei. Quando chegava à reunião, acidentalmente, Giges girou o entrave do anel, que imediatamente o fez invisível, repetiu o movimento e voltou a ser visível. Ao descobrir o poder da invisibilidade, o pastor tratou imediatamente de se aproveitar dele. Solicitou, então, que fosse ele o representante dos pastores a entregar o relatório ao rei. Chegando ao castelo, falou com a rainha, instigou um complô contra o rei, assassinou-o, tomando o trono e a rainha para si (PLATÃO, 2000).

Os mitos narrados por Platão objetivam conduzir as pessoas a enxergarem além das aparências sensíveis, ou seja, para ele o mundo inteligível é o verdadeiro, o que ele chamaria de essência, e o mundo sensível, que é o das aparências, está sujeito ao engano, ao erro e, consequentemente, à injustiça (PLATÃO, 2000). Na filosofia clássica, os mitos explicam ideias complexas de forma simples. A proposta aqui é enxergar além do mundo das aparências. No mito apresentado, Platão revela seu primeiro ensinamento: "os fins não justificam os meios". Giges ao ser injusto, utilizando de forma inescrupulosa o poder adquirido pelo anel, foi beneficiado, porém o poder adquirido e o prestígio não 
serão vantajosos se considerados "como" foram adquiridos. Para Platão, nenhum ato de injustiça pode trazer benefícios. Vive-se, na atualidade, a realidade de muitas crises. A Climática, anunciada, há muito, por inúmeros estudiosos da área, é um prelúdio da extinção da vida planetária e a Sanitária, a maior crise de saúde que o mundo já presenciou, com a COVID-19. Ambas as crises estão envoltas em um emaranhado de argumentos amparados pelo falacioso discurso de manutenção econômica. $O$ anel proporcionou a Giges o poder de invisibilidade, que, a partir do poder e sem nenhum pudor, adquiriu aquilo que procurava, riqueza material e status social, justificado diante da "sua condição de humilde pastor de ovelhas". O capitalismo, da mesma maneira, utiliza suas formas de poder para invisibilizar questões que divergem de sua ideologia e, sem nenhum pudor, justifica todos os meios, ludibriando mentes menos preparadas.

A Crise Climática, é um dos temas mais importantes e desafiadores do nosso tempo, sendo um fenômeno que alcança desde a produção de alimentos, até o aumento do nível do mar, potencializando o risco de inundações e desastres (ONU, 2019). A discussão climática está vinculada diretamente ao fator econômico, desde Paul Crutzen, com a definição de uma nova era geológica, o Antropoceno $^{5}$ (ANGUS, 2016) a Jason Moore (2018), contrapondo com o Capitaloceno $^{6}$, que as discussões sobre a interferência do ser humano no aquecimento terrestre é uma realidade, sendo, então, imprescindível que as questões relacionadas à Crise Climática sejam vinculadas ao modelo econômico, o capitalismo. A ação do ser humano tem alterado as variantes naturais do planeta, e uma delas é o clima.

Com a Revolução Industrial, no final do século XVIII e, sobretudo, no século XX, após a II Guerra Mundial, ocorreu um aumento significativo da produção industrial e da agricultura e, consequentemente, um aumento dos gases de efeito estufa na atmosfera. Essa nova fase na história da humanidade, o período industrial, trouxe um modelo de desenvolvimento e de padrões de consumo que se sustenta no uso excessivo de combustíveis não renováveis e assim contribuem para a elevação dos níveis de dióxido de carbono $\left(\mathrm{CO}_{2}\right)$ e de outros gases causadores do efeito estufa, que provocam as Mudanças Climáticas (TAMAIO, 2013, p.15).

5 O químico holandês Paul Crutzen, popularizou o termo antropoceno, determinando uma nova era geológica. Foi a primeira vez que se pensou a possibilidade de as mudanças ambientais estarem ligadas à ação humana. Disponível em: <http://www.comciencia.br/ciencia-e-sociedade-do-antropocenotransicao-partir-do-holoceno/>. Acesso em 25 ago. 2020.

6 Ainda dentro do conceito de responsabilização humana, levantou-se a possibilidade de se discutir não somente a responsabilidade humana, mais o padrão que os leva a destruir seu próprio meio, a partir daí se sugere que a era geológica presente, na verdade é a era do capitaloceno, é o que afirma o historiador e geógrafo norte americano, Jason Moore, é o capitalismo quem criou a crise ecológica global, causando a destruição ambiental. MOORE, Jason. Entrevista: Antropoceno ou capitaloceno. Sinpermiso. 2018. Disponível em: <https://www.sinpermiso.info/textos/antropoceno-mas-bien-capitaloceno-entrevista>. Acesso em 25 ago. 2020. 
A Terra aquece através de um processo natural e a capa que a protege da radiação solar, através da formação de gases e água na atmosfera, impede que o calor da radiação absorvido pela Terra escape para o espaço. Esse efeito estufa é responsável pelo equilíbrio da temperatura na Terra, impedindo que ela se esfrie demais ou que a radiação excessiva a prejudique. Dessa maneira, todas as formas de vida no planeta encontram um ambiente saudável para se desenvolverem. O problema está no aumento desses gases ocasionados pela ação humana. A queima de combustíveis fósseis, as alterações no uso do solo e lixos em aterros são alguns dos causadores do aumento dos gases, resultando no aquecimento da Terra e, consequentemente, colocando em risco toda a vida existente (SATO; SILVA; JABER, 2018).

Diante de dados comprobatórios, como se invisibiliza uma realidade de Crise do clima? Até a responsabilização do ser humano no processo de degradação ambiental, o mundo atribuía os "desastres ambientais" a fatores naturais, fato muito conveniente ao capitalismo, que continuou defendendo tal premissa, mesmo depois de se comparar os períodos sem intervenção humana, com os períodos em que o ser humano - não todo ser humano - alterou o ciclo natural do planeta. A reprodução do discurso desenvolvimentista é o maior articulador da invisibilização das Crises. Deliberadamente invisibilizadas pelo capitalismo, apropriam-se do discurso ambiental, seja domesticando-o, criando termos como "Desenvolvimento Sustentável" negar a realidade de crise, utilizando da ciência. No capitalismo, discutir o "como" se chega ao resultado não é fator relevante, desde que se chegue.

É realidade a condição de extinção de toda a forma de vida no planeta, ocasionada pelo modelo de consumo instituído pelo capitalismo, que vem ao longo do tempo instrumentalizando tudo e todos, toda forma de vida torna-se produto. Em poucos meses, uma ameaça microscópica, o Coronavírus, foi capaz de abalar a estrutura ideologicamente impregnada na mente dos exploradores como também dos explorados. O mundo capitalista parou. Durante décadas, os movimentos ecologistas vêm lutando para conseguir o que um vírus foi capaz de fazer em poucos meses. As mazelas do capitalismo emergem como resultado de uma ação injusta, demonstrando o que Platão defendia, ou seja, nenhuma ação injusta pode ocasionar em benefícios, pois os fins não podem justificar os meios injustos.

A primeira lição do Coronavírus é também a mais espantosa. De fato, ficou provado que é possível, em questão de semanas, suspender, em todo o mundo e ao mesmo tempo, um sistema econômico que até agora nos diziam ser impossível desacelerar ou redirecionar. A todos os argumentos apresentados pelos ecologistas sobre a necessidade de alterarmos nosso modo de vida, sempre se opunha o argumento da

\footnotetext{
${ }^{7}$ A expressão desenvolvimento sustentável representa uma armadilha do sistema imperante: assume os termos da ecologia (sustentabilidade) para esvaziá-los. Assume o ideal da economia (crescimento) mascarando, a pobreza que ele mesmo produz (BOFF, 2012, p.1).
} 
força irreversível do "trem do progresso", que nada era capaz de tirar dos trilhos, "em virtude", dizia-se, "da "globalização". Ora, é justamente seu caráter globalizado que torna tão frágil o famoso desenvolvimento, o qual, ao contrário, pode sim ser desacelerado e finalmente parado (LATOUR, 2019, p.1).

Em março de 2020, a OMS (Organização Mundial de Saúde) decretou estado de pandemia mundial. O Coronavírus, causador de doença respiratória COVID-19, revelou a fragilidade não só humana, mas também a do modelo econômico. Em casos mais graves, a doença pode provocar síndrome respiratória aguda grave e, nesses casos, os mais vulneráveis são pessoas com doenças pré-existentes, como hipertensão, diabetes, doenças respiratórias, porém o vírus não tem poupado pessoas mais jovens e que não possuem esse histórico. Em situação de colapso, ou seja, quando mesmo possuindo condição financeira, o indivíduo não consegue atendimento médico, no caso do Brasil, onde a maioria da população depende do Sistema Único de Saúde (SUS), o problema é potencializado devido à sua precarização, e mesmo não possuindo condições de atendimento a toda a população, é ele, o SUS, que tem salvado muitas vidas (RECONHECER..., 2020). Diante da trágica realidade, o presidente brasileiro, em pronunciamentos nacionais, negou a Crise Sanitária e ridicularizou quem alertava para o perigo. "Em março, Bolsonaro disse que havia uma "histeria" em torno da crise pandêmica [...] Em pronunciamento sobre a pandemia, o presidente disse que não se preocupava com a "gripezinha" por ter "histórico de atleta" (GIMENES, 2020, p.1).

O discurso do chefe do executivo é em defesa da economia, não que não seja também um problema, porém não é possível desconsiderar ou invisibilizar o número de vítimas fatais da pandemia, que cresceu, consideravelmente, em poucos meses, assim como o número de infectados. O discurso de preocupação com a manutenção da economia desvela o real interesse do capital: manter a produção, desconsiderando, que é o trabalhador, ignorado e explorado, quem produz riqueza e a consome, fazendo girar a economia.

As experiências de outros países e orientações da OMS revelam que os Estados que adotaram a quarentena e o distanciamento social conseguiram achatar a curva de crescimento do vírus, permitindo ao sistema de saúde uma preparação para atender os casos mais graves. Diante do desconhecido, os mecanismos de defesa se construíram a partir das experiências de outros lugares. No início de maio de 2020, a BBC reporta o número de mortos e infectados no país: "O total de mortes confirmadas por covid-19 é de 6.750. Desses óbitos, 421 foram confirmados nas últimas 24 horas, um aumento de $7 \%$. A taxa de mortalidade (a relação entre mortes por casos confirmados) é de $7 \%$ no país" (NÚMERO..., 2020, p.1).

Para o doutor em microbiologia pela USP, Átila lamarino, "A Covid mata de 10 a 20 vezes mais que o vírus da gripe comum, hospitaliza de 10 a 20 vezes mais pessoas que a gripe comum, então ela satura o Sistema de Saúde muito rapidamente" (A COVID..., 2020). O pesquisador estava certo; o vírus se 
espalhou rapidamente. Com uma população inteira incentivada a não cumprir as regras de distanciamento social, a não fazer o uso de máscaras, pelo seu líder máximo, os resultados não poderiam ser positivos. Então a morte de muitos cidadãos brasileiros está justificada em nome da manutenção do sistema econômico? Os fins justificam os meios?

\section{Entre a essência e a aparência: os negacionistas}

"Pois a mais consumada injustiça é parecer alguém justo sem o ser."

Platão

A segunda lição de Platão está voltada para a questão da essência e da aparência. Para o filósofo, o mundo inteligível é o verdadeiro, o que ele chama de essência, e o mundo sensível, que é o da aparência, está sujeito a erros e enganos. Dentro dessa perspectiva, pode-se afirmar que importante não é parecer justo, mas ser justo de verdade. Assim, na analogia de parecer algo que não é verdadeiramente, é que surgem os negacionistas ${ }^{8}$ do clima e da ciência.

Em tempos de obscurantismo ${ }^{9}$, há os que negam a existência do aquecimento global. Mesmo diante de fatos e dados científicos, não acreditam na intervenção humana, na degradação das estruturas naturais e no estímulo de um modelo de vida voltado para o consumo e para a exploração da natureza e de seres humanos. Com o objetivo de negar e descredibilizar as pesquisas voltadas à comprovação dos impactos do ser humano e do capitalismo no meio ambiente, os negacionistas criam dúvidas e contribuem para a permanência do status quo do capitalismo e da exploração da natureza (DALA-NORA, 2018).

Um estudo sobre a Crise Climática, divulgado no ano de 2013, com base na análise de publicações científicas das últimas duas décadas, revelou que $99 \%$ dos artigos na área apontam a ação humana como a causa das mudanças climáticas; um contraponto diante dos chamados "negacionistas" do clima, que atribuem o aquecimento da Terra a fatores naturais. O estudo em questão traz a análise do pós-doutorando em astrofísica na Universidade de Queensland, na Austrália, John Cook, publicado no jornal científico Environmental Research Letters: (CÉTICOS..., 2013):

${ }^{8}$ Os negacionistas do clima são as pessoas que não acreditam no aquecimento global decorrente da intervenção humana. Também podem ser chamados assim os indivíduos que creem no aumento da temperatura, mas contradizem o fato de que o fenômeno é provocado pelo homem (DALA-NORA, 2018).

${ }^{9}$ Ao longo da história humana, os governos obscurantistas são os mais autoritários e violentos. Eles prescindem da política e, portanto, do diálogo, pois suas ações se dirigem ao extermínio daqueles que consideram adversários ou dos que são "diferentes" do padrão estabelecido, qualquer que seja o assunto, pelos que se consideram os "senhores do tempo e da história". Texto do Pensar Educação. Disponível em: <https://pensaraeducacao.com.br/pensaraeducacaoempauta/governo-bolsonaro-obscurantismoque-mata/>. Acesso em 25 ago. 2020.

revista brasileira educação ambiental 
Ele avaliou o abstract, o resumo do conteúdo de 11.944 artigos científicos sobre aquecimento global e mudanças climáticas publicados entre 1991 e 2011. A avaliação de todo esse volume de material, disponível no banco de dados científico Web of Knowledge, revelou que $66,4 \%$ das publicações posicionaram-se em concordância a corrente do aquecimento global antropogênico, ou seja, causado pelo homem. Outros $32,6 \%$ dos artigos pesquisados endossava essa posição. Cook encontrou apenas $0,7 \%$ das publicações negando a participação humana no aquecimento global e $0,3 \%$ expressando incerteza quanto às reais causas das mudanças climáticas (CÉTICOS..., 2013, p.1).

Os resultados alcançados por Cook revelam que as publicações contrárias à responsabilização do ser humano pela degradação ambiental são mínimas. Os negacionistas do clima são menos de $1 \%$ da população científica.

O Painel Brasileiro de Mudanças Climáticas, no ano de 2011, publicou uma pesquisa sobre o físico e negacionista do clima, professor Richard Muller. O professor afirmou ficar surpreso sobre descobertas que comprovam que a temperatura média da superfície terrestre aumentou $1,5^{\circ}$ celsius ao longo dos últimos duzentos e cinquenta anos e que os seres humanos são quase inteiramente responsáveis por induzir tal fenômeno. O físico se considera, após descoberta, um cético convertido (PBMC, 2011).

O cientista citado não decidiu por conta própria negar a causa antrópica. O projeto dos "negacionistas do clima" foi financiado por empresas, donas dos meios de produção. É o que afirma Richard Muller:

O financiamento para o projeto incluiu 150 mil dólares da Fundação Charles G. Koch, criada pelo magnata americano bilionário do carvão, que também é um dos principais financiadores do Instituto Heartland, um centro de estudos que reúne céticos. A pesquisa também recebeu 100 mil dólares do Fundo para Pesquisa Inovadora do Clima, criado por Bill Gates (PBMC, 2011, p. 1)

$\mathrm{Na}$ tentativa de distorção da realidade, entram os negacionistas do clima. É preciso haver uma justificativa para a manutenção do modus operandi do sistema. Nos argumentos negacionistas, a não responsabilização humana é uma realidade, pois só assim se justifica a continuidade da exploração e degradação do planeta, com a afirmação de que o aquecimento da Terra se dá de forma natural e não provocada. Dentro de seus laboratórios e com o status de cientistas, o discurso fica disfarçado de altruísmo e de busca pelo conhecimento científico. A educadora ambientalista Michèle Sato, entrevistada da pesquisa a qual este artigo participa, afirma que: 
Então vem a negação da questão ambiental, inclusive o golpe e o clima, são exatamente a comprovação disso, por que, que existem negacionistas do clima? Com $97 \%$ dos cientistas afirmando que o ser humano tem influência direta no ambiente e por que 3\% dos cientistas dizem que não? Eu fui estudar esses 3\%. Estudei com Pierre Girard, que é um geólogo do Canadá, nós estudamos juntos, na verdade o Pierre que deu os textos para eu ler, e nós discutimos juntos.

Com a maioria das pesquisas comprovando a realidade da influência humana nas alterações climáticas, ainda assim há quem conteste. Até aqui, não há problema algum. O método científico pressupõe refutação. O problema está na não consistência dessas alterações, assim como no percentual mínimo de quem se opõe e de financiadores. A educadora citada continua explicando a origem desses negacionistas do clima e suas intencionalidades:

Então, aí a gente chegou à constatação que os $3 \%$ dos negacionistas, eram geólogos do petróleo, e que tinham pesquisa em andamento, em desenvolvimento, e muito dinheiro por sinal, inclusive com enriquecimento ilícito dessas pessoas que faziam pesquisa. E por que isso? Porque eram geólogos do petróleo muito ligados a EXXON. A EXXON é a companhia petrolífera que está destruindo os pólos, hoje nós temos $40 \%$ da extinção dos ursos polares, e as calotas polares, em franco degelo assustador.

Partindo do que afirmou a educadora, os cientistas que contrapõem o conceito de intervenção humana, que causa a Crise Climática afirmada também por cientistas, não estão a serviço da ciência, mas a mando do capital, cujo intuito, a todo custo, é o de enriquecer, ampliando o abismo social e tornando os menos favorecidos na pirâmide social mais vulneráveis às catástrofes climáticas. Os negacionistas brasileiros são comandados pelo professor Luiz Carlos Molion, já aposentado da Universidade Federal de Alagoas. Segundo o Observatório do Clima, o grupo enviou uma carta para o Governo Federal demandando "inação climática já!" (ÂNGELO, 2019).

Eles argumentam que não há evidências físicas da influência humana no clima global, que essa hipótese causa um "risco às políticas públicas" e o governo deveria investir dinheiro para pesquisar coisas mais relevantes, como o que aconteceu com o clima 2,6 milhões de anos atrás. A carta é assinada por 20 pessoas que o site "Notícias Agrícolas" chamou de "cientistas brasileiros", liderados pelo meteorologista Luiz Carlos Molion, professor aposentado da Universidade Federal de Alagoas. É endereçada, com esperança, ao ministro do Meio Ambiente, Ricardo Salles, que tem sistematicamente manifestado que o aquecimento global é uma discussão "acadêmica". Nessas duas dezenas de bravos há 6 geógrafos, 4 meteorologistas, 3 geólogos, 3 físicos, 1 agrônomo, 1 biólogo, 1 engenheiro eletricista e 1 jornalista. Apenas seis, com boa vontade para entender sobre climatologia (ÂNGELO, 2019, p.1).

Revbea, São Paulo, V.16, № 5: 247-269, 2021.

revista brasileira

educação ambiental 
O professor Molion vive hoje dando palestras a sojicultores do cerrado brasileiro. Em uma explicação resumida, segundo o professor, o aquecimento ocorrido é natural e a cobertura de nuvens faz o resfriamento da Terra. A tendência daqui em diante, segundo ele, não é o aquecimento da Terra, mas o resfriamento. Ainda afirma que os índices do IPCC sobre a emissão de CO2 e a responsabilização humana pelo aumento são imprecisos, atrapalhando o desenvolvimento econômico do país (AGÊNCIA SENADO, 2019). Para o educador ambientalista Marcos Sorrentino, também entrevistado da pesquisa:

[...] tem um grupo que é minoritário, mas que tem um poder imenso, porque eles são bancados, porque eles trabalham com a anti-ciência, são bancados pelas grandes corporações petrolíferas, que é aquilo que nós chamamos de negacionista. Antigamente se chamavam céticos, mas não são céticos, porque eles não trabalham a lógica da ciência, eles são de fato negacionistas [...].

Percebe-se que os argumentos dos negacionistas brasileiros estão ligados diretamente aos fatores econômicos e não exatamente às questões científicas de fato. Em contraponto, na mesma audiência com os negacionistas, o astro-geofísico Gylvan Meira, colaborador do IPCC até o ano de 2015, alertou: "[...] EUA, país que mais abriga negacionistas no mundo, tradicionalmente ligados ao lobby de poderosos setores industriais. O que não impede de avançar nas pesquisas tratando do impacto humano para o acúmulo de CO2" (AGÊNCIA SENADO, 2019, p.1). As pesquisas científicas que relacionam a ação humana ao aumento de emissão de gases poluentes na atmosfera são muito bem alicerçadas e não dizem respeito a teorias sem embasamento científico - um dos argumentos dos cientistas brasileiros em audiência no Senado Federal:

É importante ressaltarmos que esta é uma área de investigação muito ativa mundialmente. A cada semana são publicados pelo menos quatro ou cinco papers de impacto internacional. Só nos últimos seis meses, foram divulgados trabalhos de pesquisas coletando esforços de quase três mil cientistas, todos apontando questões preocupantes quanto à sustentabilidade ambiental no que tange às atividades humanas. A experiência indica que é improvável que três mil cientistas estejam equivocados em suas investigações, e apenas dois ou três estejam corretos - afirmou Paulo Artaxo, físico do Instituto Nacional de Pesquisas Espaciais (Inpe), que também colabora junto ao Painel Intergovernamental sobre Mudanças Climáticas (IPCC), da ONU (AGÊNCIA SENADO, 2019, p.1).

Negar a ciência é prática recorrente também do presidente da República. Como já mencionado, este, desde a declaração de pandemia, vem estimulando a população a não cumprir o isolamento social. Realidade defendida pelo seu 
primeiro-ministro da Saúde ${ }^{10}$ no início da crise no país. Ministro que foi demitido. Seu segundo ministro pediu demissão em menos de um mês no cargo. $O$ Ministério da Saúde também foi dirigido por um general, que compartilha das ideias do presidente. Depois de diminuir a gravidade do problema em rede nacional, o presidente da República tem sido contra as maiores lideranças mundiais, ao ponto de ser considerado, pelo jornal Washington Post, o pior líder global a lidar com o coronavírus (PRUDENCIANO, 2019).

$\mathrm{Na}$ tentativa de "parecer bom", o Governo Federal, depois de muita pressão, aprovou o auxílio emergencial como se fosse uma iniciativa própria. $\mathrm{O}$ deputado Marcelo Aro do Partido Progressista de MG foi quem apresentou, na câmara dos deputados, seu substitutivo ao Projeto de Lei 9236/17, incorporando ao texto a concessão de um auxílio emergencial por três meses, no valor de $\mathrm{R} \$$ 500,00 , a pessoas de baixa renda (CÂMARA..., 2020), o qual, antes dessa aprovação, foi ofertado a $\mathrm{R} \$ 200,00$ pelo Ministro da Economia Paulo Guedes, para trabalhadores informais. Assim, esses representantes, envergonhados com a ação dos deputados da oposição que exigiam uma ação significativa e humana por parte do governo, resolvem liberar R\$ 600,00 (TEMÓTEO; MILITÃO, 2020). Mais uma vez, tentando parecer ser justo, o presidente se vale da ação de deputados federais, como se o governo estivesse fazendo um favor ao povo com o dinheiro público. Nos dois exemplos tratados, tanto dos negacionistas do clima quanto do negacionismo da ciência em uma pandemia, afirma-se o ensinamento de Platão, quando ratifica que o mundo das aparências está sujeito a erros, enganos e injustiças, e a mais consumada injustiça é parecer alguém justo e não o ser.

\section{Tornar visível: o poder revela a índole}

"Quer saber quem é a pessoa? Ihe dê poder."

Platão

Giges, enquanto pastor de ovelhas, não era justo na essência, e a afirmação pode ser observada pelo resultado posterior, quando este, em posse do anel, demonstrou ser injusto. Antes do poder adquirido, Giges era ou parecia ser "justo", apenas por força da lei e pelas consequências, sendo "justo" não por

10 Segundo o ministro da Saúde, Luiz Henrique Mandetta, os números mostram que o crescimento não está ocorrendo de forma localizada, mas no conjunto do país. "Estamos vendo uma tendência mais nacional. Se levantar em bloco vai ser muito mais difícil de monitorar", declarou. Com isso, continuou o ministro, o papel dos cidadãos ganha importância nas medidas de prevenção, como higienização, e de contenção, como o isolamento. Isso porque a preocupação é com a sobrecarga do sistema de saúde. Agência Brasil EBC. 2020. Disponível em: <https://agenciabrasil.ebc.com.br/saude/noticia/202003/acompanhe-ao-vivo-brasil-tem-621-casos-confirmados-de-covid19-seis-mortes>. Acesso em 25 ago. 2020 . 
vontade própria, mas por obrigação. Ao ser injusto, ele evidencia que sua ação não era boa, pois os meios que ele utilizou para realizar seus desejos não eram bons. O correto para Platão seria ser justo enquanto ninguém o visse e sua ação deveria estar em consonância com o meio utilizado. Ao descobrir o poder de invisibilidade, Giges revela sua índole (PLATÃO, 2000). Verdade também descortinada quando tratamos das reais intenções dos negacionistas climáticos. Sua índole se revela, ao evidenciar os patrocinadores de suas pesquisas, 0 capital por trás do negacionismo climático - o mesmo capital por trás dos discursos negacionistas do atual presidente do Brasil e de seus seguidores. $O$ poder presidencial concedido desencadeou o desmonte de mais de trinta anos de conquistas de políticas públicas ambientais, revelando a índole exploratória e predatória do capital. Na realidade da pandemia, o poder do anel presidenciável dissemina notícias falsas, pesquisas sem comprovação, ódio à ciência, apologia à ignorância e, consequentemente, mortes.

$\mathrm{Na}$ intencionalidade de denúncia, registram-se as principais violações ao meio ambiente desse período, quando Ricardo Salles, ministro do Meio Ambiente, esteve à frente da pasta, na expectativa de combatê-las e, quem sabe, a longo prazo, de reverter as que forem possíveis. Muitos são os exemplos das violações na área ambiental brasileira ${ }^{11}$ : o esvaziamento da pasta do Meio Ambiente, desestruturando o IBAMA ${ }^{12}$, o $\operatorname{ICMBIO}^{13}$ e outros órgãos, com a retirada da autonomia dos servidores no que tange às questões de fiscalização ambiental; a extinção de alguns órgãos, contrariando a própria Constituição Federal, em seu artigo $6^{0}$ da lei 6.938/81, redação dada pela Lei $8028 / 90^{14}$,

11 A reforma ministerial da Gestão Bolsonaro (MPV 870/2019) possibilita o desmonte e o controle por ruralistas de órgãos ambientais, direitos de populações indígenas e tradicionais. O Ministério do Meio Ambiente (MMA) é esvaziado de competências e perde a capacidade de formular e conduzir algumas políticas fundamentais para as competências históricas (e lógicas) da pasta. A Secretaria de Mudanças do Clima e Florestas é extinta, além disso, o SFB (Serviço Florestal Brasileiro) e o CAR (Cadastro Ambiental Rural) vão para o MAPA e a Agência Nacional de Águas (ANA) vai para o Ministério do Desenvolvimento Regional (MDR). A FUNAI deixa o Ministério da Justiça e de Segurança Pública (MJSP) e vai para o Ministério da Mulher, da Família e dos Direitos Humanos. A competência de demarcação de terras indígenas, contudo, vai para o MAPA. Disponível em: $<$ https://www.socioambiental.org/pt-br/blog/blog-do-isa/a-anatomia-do-desmontedas-politicassocioambientais >. Acesso em 25 ago. 2020.

12 Instituto Brasileiro do Meio Ambiente e dos Recursos Naturais Renováveis, mais conhecido pelo acrônimo IBAMA, criado pela Lei ํㅜ 7.735 de 22 de fevereiro de 1989, é uma autarquia federal vinculada ao Ministério do Meio Ambiente (MMA). É o órgão executivo responsável pela execução da Política Nacional do Meio Ambiente (PNMA (MMA).

${ }^{13}$ Instituto Chico Mendes de Conservação da Biodiversidade é uma autarquia em regime especial vinculada ao Ministério do Meio Ambiente e integrada ao Sistema Nacional do Meio Ambiente (MMA).

${ }^{14}$ Art. 6ํㅡㅇ Os órgãos e entidades da União, dos Estados, do Distrito Federal, dos Territórios e dos Municípios, bem como as fundações instituídas pelo Poder Público, responsáveis pela proteção e melhoria da qualidade ambiental, constituirão o Sistema Nacional do Meio Ambiente - SISNAMA, assim estruturado: I - órgão superior: o Conselho de Governo, com a função de assessorar o Presidente da República na formulação da política nacional e nas diretrizes governamentais para o meio ambiente e os recursos ambientais; (Redação dada pela Lei no 8.028, de 1990 . II - órgão consultivo e deliberativo: o Conselho Nacional do Meio Ambiente (CONAMA), com a finalidade de assessorar, estudar e propor ao Conselho de Governo, diretrizes de políticas governamentais para o meio ambiente e os recursos naturais e deliberar, no âmbito de sua competência, sobre normas e padrões compatíveis com o meio ambiente ecologicamente equilibrado e essencial à sadia qualidade de vida; (Redação dada pela Lei no 8.028, de 1990). III - órgão central: a Secretaria do Meio Ambiente da Presidência da República, com a

Revbea, São Paulo, V.16, № 5: 247-269, 2021. 
dispondo sobre a Política Nacional do Meio Ambiente; a transferência do serviço Florestal brasileiro do Ministério do Meio Ambiente para o Ministério da Agricultura; e a redução e flexibilização de penas por crimes ambientais, através de um decreto presidencial, que podem alterar o valor da multa aplicada ou até mesmo a exclusão dela (AGÊNCIA SENADO, 2019).

O Decreto 9.760 , de 2019, estabelece que os órgãos vinculados ao Ministério do Meio Ambiente, como o Instituto Brasileiro do Meio Ambiente e dos Recursos Naturais Renováveis (Ibama) e o Instituto Chico Mendes de Conservação da Biodiversidade (ICMBio) são obrigados a estimular a conciliação nos casos de infrações administrativas por danos ambientais e seguir um rito estabelecido para encerrar os processos (AGÊNCIA SENADO, 2019, p.1).

O desmonte continua, pois o INPE (Instituto nacional de Pesquisas Espaciais), órgão responsável pelo monitoramento da Amazônia, divulgou os dados oficiais de desmatamento no ano de 2019, que indicavam uma forte aceleração nos últimos dois meses. Esses dados foram refutados pelo então presidente, que se pronunciou afirmando que os dados do INPE eram "mentirosos" e continuou dizendo que "o diretor do instituto deveria estar a serviço de alguma ong". O diretor foi exonerado de seu cargo (EXONERAÇÃO..., 2019).

O fundo bilionário ${ }^{15}$ da Amazônia foi interrompido, outro retrocesso para o meio Ambiente, e o financiamento de projetos de proteção da região foi cancelado por conta do aumento do desmatamento, o qual tem sido fomentado pela desregulamentação política, recriminando a ação de fiscais ambientais que combatem madeireiros e garimpeiros que atuam na região (NEGRÃO, 2019).

A falácia de regularização fundiária é outro desmonte. Trata-se de uma Medida Provisória que concede a grileiros, via autodeclaração, o direito de legalizar terras apropriadas ilegalmente, assim como a proposta de redução das terras indígenas e áreas remanescentes quilombolas, aumentando os conflitos e, consequentemente, a violência no campo e contra os indígenas. Em audiência pública no Senado, representantes das comunidades envolvidas se pronunciaram a respeito da MP 910/2019:

finalidade de planejar, coordenar, supervisionar e controlar, como órgão federal, a política nacional e as diretrizes governamentais fixadas para o meio ambiente; (Redação dada pela Lei no 8.028, de 1990). Disponível em: <http://www.planalto.gov.br/ccivil 03/leis/L8028compilada.htm>. Acesso em 25 ago. 2020.

15 O Fundo Amazônia tem por finalidade captar doações para investimentos não-reembolsáveis em ações de prevenção, monitoramento e combate ao desmatamento, e de promoção da conservação e do uso sustentável das florestas no Bioma Amazônia, nos termos do Decreto no 6.527, de 1ำ de agosto de 2008. O Fundo Amazônia apoia projetos nas seguintes áreas: Gestão de florestas públicas e áreas protegidas, controle, monitoramento de fiscalização ambiental, manejo florestal sustentável, atividades econômicas desenvolvidas a partir do uso sustentável da floresta, entre outros. Ministério do Meio Ambiente. Disponível em: <https://www.mma.gov.br/apoio-a-projetos/fundo-amazonia>. Acesso em 25 ago. 2020.

Revbea, São Paulo, V.16, № 5: 247-269, 2021.

revista brasileira educação ambiental 
Para Oriel Rodrigues de Moraes, advogado da Coordenação Nacional de Articulação das Comunidades Negras Rurais Quilombolas (Conaq), a MP contraria a Constituição. [...] É um grande desafio, um grande medo e uma grande insegurança para a gente. Imagine qualquer um ir lá e dizer que é dele as terras que os quilombolas usam há mais de 200 anos - afirmou. Elias d'Ângelo Borges, da Confederação Nacional dos Trabalhadores na Agricultura (Contag), criticou o que chamou de política de esvaziamento do Incra. Para ele, os termos da MP beneficiam quem tem mais condição econômica para solicitar a regularização de terras, o que resultaria em procedimentos que ignoram as famílias que lá vivem. [...] Saulo Ferreira Reis, representando a Comissão Pastoral da Terra (CPT), também considera a MP superficial. A autodeclaração, diz ele, pode contribuir para a grilagem de terras, pois não afere objetivamente quem tem a posse da terra (AGÊNCIA SENADO, 2020, p.1).

Dentro das retóricas dos palanques, em 2018, a prática do desmonte, a partir do ano de 2019, iniciado com o desmonte das instituições reguladoras, o afrouxamento nas políticas públicas de proteção, o avanço do agronegócio em terras protegidas, entre outros retrocessos ${ }^{16}$, tornaram-se uma bandeira justificada por discursos anti-intelectuais. 2019 foi o ano de cumprir as ameaças de palanque. Sobre as características do candidato eleito em 2019, o sociólogo Ivann Lago, da Universidade Federal da Fronteira Sul (UFFS), afirma:

O Brasil levará décadas para compreender o que aconteceu naquele nebuloso ano de 2018, quando seus eleitores escolheram, para presidir o país, Jair Bolsonaro. Capitão do Exército expulso da corporação por organização de ato terrorista; deputado de sete mandatos conhecidos não pelos dois projetos de lei que conseguiu aprovar em 28 anos, mas pelas maquinações do submundo que incluem denúncias de "rachadinha", contratação de parentes e envolvimento com milícias; ganhador do troféu de campeão nacional da escatologia, da falta de educação e das ofensas de todos os matizes de preconceito que se pode listar (LAGO, 2020, p.1).

Em junho de 2019, em sessão especial do Plenário, sessão essa em que se celebrava o "Dia Mundial do Meio Ambiente", ambientalistas e parlamentares reclamam da política adotada pelo governo, a exemplo de ações defendidas ou atribuídas pelo poder executivo, como o fim da demarcação de terras indígenas,

${ }^{16} \mathrm{O}$ atual cenário político e socioambiental brasileiro demonstra o resultado do desmonte realizado pelo Governo Bolsonaro, os ataques constantes contra os órgãos e entidades socioambientais, além dos discursos contra a atuação dos servidores e as normas ambientais. Desde 2019, com o início do atual governo, tem havido um aumento em número e extensão dos incêndios florestais, expansão do desmatamento da Amazônia; A ASCEMA Nacional redige Dossiê sobre desmonte ambiental brasileiro durante o governo Bolsonaro. Segue lista com as desregulamentações ambientais. Disponível em: <https://static.poder360.com.br/2020/09/Dossie Meio-Ambiente Governo-Bolsonaro revisado 02-set2020-1.pdf>. Acesso em 25 ago. 2020. 
a flexibilização de licenciamentos ambientais, alterações do código florestal, assim como mudanças no fundo da Amazônia (AGÊNCIA SENADO, 2019). Para Carlos Rittl, secretário-geral do Observatório do Clima, o Brasil "vive tempos de obscurantismo e negacionismo":

Isso faz com algumas das mais altas autoridades do governo desmonte deliberadamente um legado de 30 anos de governança ambiental no Brasil, construído com imensa contribuição do Parlamento brasileiro. $\mathrm{O}$ Brasil sofreu prejuízos de $R \$ 278$ bilhões nos últimos dez anos em função de eventos climáticos extremos. De 2013 a 2017, 2.706 municípios sofrem com secas severas. No mesmo período, 1.726 sofreram com alagamentos. Mudanças climáticas são reais, causam impactos - afirmou (AGÊNCIA SENADO, 2019, p.1).

É explícita a intencionalidade de interromper ou descredibilizar as instituições e os programas de regulamentação ou contenção de danos ambientais em que se concentram as ações do governo atual, que nomeou um negacionista para ministro do Meio Ambiente ${ }^{17}$ e uma ruralista ${ }^{18}$ para o Ministério da Agricultura. Para Jacobi (2005), a crise ambiental estabelecida está ligada diretamente ao sistema econômico de exploração, sendo o Brasil um dos países mais desiguais e injustos em distribuição de renda:

Assim, o que se observa é que, enquanto se agravavam os problemas sociais e se aprofundava a distância entre os países pobres e os industrializados, emergiram com mais impacto diversas manifestações da crise ambiental, que se relacionam diretamente com os padrões produtivos e de consumo prevalecentes (JACOBI, 2005, p.4).

17 Durante a reunião ministerial do dia 22 de abril, o ministro do Meio Ambiente, Ricardo Salles, alertou os ministros sobre o que considerava ser uma oportunidade trazida pela pandemia da Covid-19: para ele, o governo deveria aproveitar o momento em que o foco da sociedade e da mídia está voltada para o novo coronavírus para mudar regras que podem ser questionadas na Justiça, conforme vídeo divulgado nesta sexta-feira pelo ministro do Supremo Tribunal Federal (STF) Celso de Mello. Segundo ele, seria hora de fazer uma "baciada" de mudanças nas regras ligadas à proteção ambiental e à área de agricultura e evitar críticas e processos na Justiça. "Tem uma lista enorme, em todos os ministérios que têm papel regulatório aqui, para simplificar. Não precisamos de Congresso", disse o ministro do Meio Ambiente. "Passando a boiada". Reportagem disponível em: <https://g1.globo.com/politica/noticia/2020/05/22/ministro-do-meio-ambiente-defende-passar-a-boiadae-mudar-regramento-e-simplificar-normas.ghtml>. Acesso em 07 de setembro de 2020.

18 A ministra da Agricultura, Tereza Cristina, disse que haverá cada vez mais aprovação de registros de defensivos agrícolas, o que é necessário para o Brasil "entrar na modernidade". Depois de polêmica criada após a liberação de novos defensivos, a ministra alegou que os produtos autorizados atualmente têm menos toxicidade e são melhores para o País. Reportagem disponível em: $<$ https://exame.com/brasil/consumidor-nao-esta-sendo-impactado-diz-tereza-cristina-sobreagrotoxicos/>. Acesso em: 07 set. 2020.

Revbea, São Paulo, V.16, № 5: 247-269, 2021.

revista brasileira

educação ambiental 
O descaso com o meio ambiente, consequentemente, revela o descaso com toda forma de vida. A defesa do modelo econômico capitalista exige um preço e, no que diz respeito ao poder exercido pelo Governo Federal atual, o pagamento não será efetuado por todos. Quanto à crise climática, a população em condição de vulnerabilidade já é a mais afetada.

Grupos sociais em maior vulnerabilidade socioeconômica frequentemente são também mais vulneráveis a eventos tais como enchentes, secas prolongadas, falta de disponibilidade hídrica, variação na quantidade e no preço dos alimentos e variações nas dinâmicas de recursos naturais específicos. Tais eventos estão sendo intensificados com o advento das mudanças do clima, e tendem a ser cada vez mais frequentes e intensos à medida que essas mudanças se acentuam (MILANEZ, 2010, p.4).

Diante do histórico de negação das duas crises abordadas, as consequências já são sentidas, especialmente pelos mais vulneráveis. A crise pandêmica trouxe o questionamento que muitos ambientalistas já fazem há algum tempo: há possibilidade de redução no modo exploratório e insustentável pelo qual o planeta é submetido? Porém, os capitalistas também se aproveitam do momento de crise, é o que afirma Latour (2020):

Infelizmente, não são só os ecologistas que veem nessa pausa súbita no sistema de produção globalizado uma grande oportunidade de fazer avançar seu programa de aterrissagem. Os adeptos da globalização, aqueles que, em meados do século XX, inventaram a ideia de escapar das restrições planetárias, também veem nela uma excelente oportunidade de se desvencilhar ainda mais radicalmente do que resta de obstáculos à sua fuga para fora do mundo. Para eles, essa é uma oportunidade boa demais de se livrarem do resto do Estado social, da rede de segurança dos mais pobres, do que ainda resta de regulamentação contra a poluição e, mais cinicamente ainda, de se livrarem de toda essa gente em excesso que atulha o planeta (LATOUR, 2020, p.1).

Em maio de 2020, o Brasil registrou seiscentas mortes por Covid-19 em apenas 24 horas, somando, no total, 7.921 óbitos e quase 115 mil casos registrados. Também, devem-se considerar aqui os casos de subnotificação, tornando os números muito maiores do que os já apresentados pelo Ministério da Saúde (BRASIL...,2020). Em agosto de 2020, o país continua a sofrer com uma curva crescente de contaminação e mortes em muitos estados com a triste marca de mais de mil mortes, em 24 horas, sendo registradas mais de cem mil mortes, com quase três milhões de infectados no Brasil (MELO, 2020). Em setembro de 2020, o vírus já havia contaminado mais de quatro milhões de pessoas no Brasil e, desse montante, mais de cento e trinta mil pessoas morreram. Todos os países no mundo foram condicionados a adotar a medida 
de isolamento social. O Brasil, que registrou o primeiro caso em fevereiro, segue ainda com um número crescente de óbitos e o país registra quase novecentas mortes, em apenas vinte e quatro horas (BRASIL..., 2020). Com vacinas ainda em testes, o país segue refém da teoria de um remédio "milagroso" ofertado pelo presidente. O mundo inteiro vive a crise e nenhum laboratório no mundo comprovou a eficácia da hidroxicloroquina ${ }^{19}$. Nesse contexto, o que torna ainda mais absurdo é a compra de um medicamento sem comprovação científica de sua eficácia. De acordo com Pontes (2020), ele foi "adquirido da Índia, sem licitação, custou seis vezes mais que o valor pago no ano passado. Finalizada no laboratório químico do Exército, a produção do comprimido aumentou 84 vezes em relação ao ano passado" (PONTES, 2020, p.1).

Em outubro de 2020, o país chega à marca de cento e cinquenta mil mortos por Covid-19 e cinco milhões de infectados. Segundo especialistas, considerando as subnotificações, os números podem ser alterados consideravelmente (LEMOS; BARRUCHO, 2020). Ao que parece, não era só uma "gripezinha". Lembrando Platão, "quer saber quem é uma pessoa? Ihe dê poder". Seria a explicação para o descaso com o meio ambiente e com a vida humana? O poder concedido pelo capital corrompeu e instrumentalizou tudo à sua volta, e até mesmo os que apenas pensam que o possui reproduzem seu discurso.

Em julho de 2021, a "gripezinha" anunciada pelo chefe do executivo ainda não havia passado, mas uma CPI (Comissão Parlamentar de Inquéritos) foi aberta para investigar possíveis crimes relacionados ao combate da pandemia no país, depois do descaso e descrédito com o único meio de combate ao vírus, a vacina. A pasta da saúde é dirigida pelo quarto ministro, momento em que se enfrenta uma nova variante do vírus. Já existem algumas vacinas, porém, como a demanda mundial foi grande e a compra por parte dos governantes demorada, o país iniciou tardiamente a vacinação ${ }^{20}$ da população, apresentando um percentual muito aquém do esperado para conter a contaminação. Com uma média de aproximadamente mil e quatrocentos óbitos em vinte e quatro horas, o país chega à marca de 554.526 mil mortos e quase vinte milhões de infectados (BRASIL TEM..., 2021, p.1).

19 Hidroxicloroquina é o sulfato de Hidroxicloroquina, um sal cristalino incolor, solúvel em água até um mínimo de 20\%, conhecido quimicamente como 2-[4-[(7-cloro-4-quinoil) amino] pentil] etilamino] etanol sulfato (1:1). Hidroxicloroquina é uma 4-aminoquinolina antimalárica com ação esquizonticida e algum efeito gametocida, sendo também considerado um antirreumático de ação lenta. Bula do remédio. Disponível em: <https://consultaremedios.com.br/hidroxicloroquina/bula>. Acesso em: 15 ago. 2020.

20 Dados divulgados pelo consórcio dos veículos de imprensa às $20 \mathrm{~h}$ deste sábado (31) apontam que $19,55 \%$ da população está totalmente imunizada contra a Covid-19. No total, 41.403.032 pessoas já receberam a segunda dose da vacina ou o imunizante em dose única. No total, a primeira dose foi aplicada em 100.677.686 pessoas em todos os estados e no Distrito Federal, o equivalente a $47,54 \%$ da população. Disponível em: <https://g1.globo.com/bemestar/vacina/noticia/2021/07/31/vacinacaocontra-a-covid-19-mais-de-100-milhoes-de-brasileiros-receberam-a-primeira-dose.ghtml>. Acesso em 25 ago. 2020.

Revbea, São Paulo, V.16, № 5: 247-269, 2021.

revista brasileira

educação ambiental 
Para Platão, nenhum ato de injustiça pode trazer benefícios, ou seja, os fins não podem justificar os meios. O discurso de desenvolvimento econômico não pode se valer da destruição e da exploração de todas as formas de vida, assim como o capitalismo não pode parecer aquilo que não é. Sendo assim, a índole desse sistema é evidenciada por seus impactos, provando que ele é desigual, sendo, então, injusto, exploratório e predatório.

\section{Conclusões}

A crise pandêmica revela o que o mundo capitalista vem tornando invisível há tempos: suas fragilidades e desigualdades. Desde a década de sessenta, ambientalistas buscam dar visibilidade às questões climáticas, denunciando o modelo de produção capitalista que sempre se mostrou insustentável. O sistema capitalista utiliza artifícios para tentar parecer sustentável e justo, porém, segundo os ensinamentos de Platão, esse é um mundo de aparências, intitulado como um mundo sensível, que está sujeito a erros, enganos e, consequentemente, a injustiças.

O sistema econômico capitalista é insustentável e injusto. Ao contrário do mundo das aparências, está o mundo das formas perfeitas, onde meios e fins são justos, onde parecer ser justo não é o suficiente e onde o poder revela a índole de quem o possui. Na perspectiva de justiça, a relação "parecer e ser" precisam ser definidas. No Brasil atual, essa relação é desnudada pelo vírus da Covid-19, em que a falta de investimentos na área de saúde, em saneamento básico e em educação comprovou a condição de injustiça por parte do sistema. $\mathrm{Na}$ condição de "parecer" justo, o presidente da República ainda defende a economia em detrimento da vida da população, sendo injusto. Mesmo quando as maiores economias se rendem à realidade de um vírus. Quem poderia imaginar que seria possível frear o sistema econômico mundial, por conta das próprias injustiças do sistema?

Daí esta incrível descoberta: havia de fato no sistema econômico mundial, escondido de todos os olhares, um sinal de alarme vermelho vivo, junto a uma grande alavanca de aço que cada chefe de Estado podia puxar de uma só vez para fazer parar "o trem do progresso" com um estridente guincho de freios (LATOUR, 2020, p.2).

Um isolamento social, causado por um vírus, permitiu a desaceleração do sistema econômico. Latour (2020) afirma a fragilidade que o sistema vem escondendo ao longo do tempo: a possibilidade de mudança. Há uma constante retórica do sistema econômico capitalista de não resistir, caso a Lei Áurea fosse assinada, ou de não gerar empregos, caso leis trabalhistas fossem aprovadas, que chegam à retórica de uma urgente reforma da previdência e trabalhista, alegando que, caso contrário, o país agravaria a crise econômica. Todavia, todos 
esses argumentos são até hoje infundados e o mundo não vai acabar caso o sistema produtivo capitalista reduza.

Esta é a hora de denunciar, aos quatro cantos do mundo, que o sistema capitalista é injusto e insustentável, que não é possível passar por uma crise como se nada tivesse acontecido. O relato feito no livro "Os condenados da Pandemia", organizado pela professora Michèle Sato, traz um panorama de grupos sociais em condição de vulnerabilidade:

A chegada do coronavírus no Brasil afetou inicialmente os grupos sociais mais favorecidos economicamente. No entanto, a doença agora se espalha de forma avassaladora junto à população desassistida e em situação de vulnerabilidade da região periférica urbana. Numa sociedade marcada pela trágica e vergonhosa desigualdade social, doenças infecciosas encontram campo fértil para a sua propagação e extermínio (SATO, 2020, p.99).

Questionar o sistema significa expô-lo também, demonstrando as desigualdades e as injustiças. É preciso questionar qual a necessidade de desmatar a floresta em nome da expansão agrícola, para o avanço da monocultura, quando somos alimentados por pequenos produtores. Com uma produção química dependente, poucos enriquecem às custas do envenenamento dos rios, do solo, do ar e de pessoas, em nome da produção de commodities para exportação. Em um país onde o MST (Movimento dos Trabalhadores SemTerra) resiste à margem da sociedade e consegue ser o maior produtor de arroz orgânico da América Latina no ano de 2019/2020, utilizando o modelo coletivista de produção, prova-se que é possível um modo de produção mais sustentável (MEDEIROS, 2020). Ainda em meio a pandemia, o MST se solidariza com os que estão em condição de vulnerabilidade, doando toneladas de alimentos agroecológicos cultivados em seus assentamentos (AGROECOLOGIA..., 2020). Diante da posição de sétimo lugar dos países mais desiguais do mundo, segundo o relatório da PNUD (Programa das Nações Unidas) (FORTE, 2020), por que não questionar a distribuição de renda e os insignificantes investimentos em educação, saúde, saneamento básico e segurança?

Se cada um de nós começar a fazer esse tipo de pergunta sobre cada aspecto de nosso sistema de produção, podemos nos tornar efetivos interruptores da globalização - tão efetivos, pois somos milhões, quanto o famoso coronavírus em sua maneira única de globalizar o planeta. O que o vírus consegue com a humilde circulação boca a boca de perdigotos - a suspensão da economia mundial - nós começamos a poder imaginar ser para nós também possível, que nossos pequenos e insignificantes gestos, acoplados uns aos outros, conseguirão: suspender o sistema produtivo. Ao nos colocarmos esse tipo de questão, cada um de nós começa a imaginar "gestos barreira", [6] mas não apenas contra o vírus: contra cada elemento de um modo de produção que não queremos que seja retomado (LATOUR, 2020, p.2)

Revbea, São Paulo, V.16, № 5: 247-269, 2021. 
É preciso que os pequenos e "insignificantes" gestos de resistência sejam unidos a muitos outros gestos, para que esse modelo destrutivo seja suspenso, como sugere Latour (2020). Pensar uma sociedade como propõe Platão pode parecer utópico, no sentido de difícil de alcançar, mas não impossível. Se um sistema econômico solidificado na maior parte do globo terrestre foi capaz de ser freado por um vírus, há possibilidade de superação desse sistema. Ainda dentro do campo das utopias, a possibilidade de uma sociedade, em que as ações justas estejam associadas aos meios que também devem ser justos, em que a essência supere a aparência - não bastando apenas parecer justo, mas ser -, e em que o poder revelará a índole justa, ainda pode ser pensada.

\section{Agradecimentos}

Nossos agradecimentos são a todos que de alguma maneira buscam transformar o mundo mais do que apenas interpretá-lo, e aos educadores/as ambientais que fizeram da pesquisa da qual este artigo participa, muito mais significativa: Michèle Sato, Marcos Sorrentino, Irineu Tamaio, Phillipe Layrargues e Heitor Medeiros. À nossas famílias, nossos adoráveis parceiros de viagem. Ao Instituto Federal de Educação de Ciência e Tecnologia de Mato Grosso/ Programa de Pós-Graduação stricto sensu, Mestrado Acadêmico em Ensino. A PROPES/IFMT pela concessão de auxílio financeiro a esta pesquisa, através do edital 46/2019, proporcionando ao estudo um auxílio fundamental ao processo de construção do conhecimento e apresentação dos resultados. Pela oportunidade agradeçemos!

\section{Referências}

A COVID mata de dez a vinte vezes mais que a gripe comum, avalia biólogo no Roda Viva. TV Cultura. 2020. Disponível em: $<$ https://tvcultura.com.br/noticias/1173 a-covid-mata-de-dez-a-vinte-vezesmais-que-a-gripe-comum-avalia-biologo-no-roda-viva.html>. Acesso em: 03 de Maio de 2020.

AGÊNCIA SENADO. Tese do aquecimento global é frágil afirma Luiz Molion.

Senado 12.2019 .2 Disponível em: $<$ https://www12.senado.leg.br/noticias/materias/2019/05/28/tese-doaquecimento-global-e-fragil-afirma-meteorologista-luiz-molion>. Acesso em: 09 de dezembro de 2019.

AGÊNCIA SENADO. Mp da regularização fundiária. Senado 12. 2020. Disponível em: <https://www12.senado.leg.br/noticias/materias/2020/03/04/mpda-regularizacao-fundiaria-divide-opinioes-em-comissao-mista>. Acesso em 04 de maio de 2020.

AGÊNCIA SENADO. Ambientalistas criticam política ambiental de Bolsonaro. Senado 12.2019 .2 Disponível em: $<$ https://www12.senado.leg.br/noticias/materias/2019/06/06/ambientalistascriticam-politica-ambiental-de-bolsonaro>. Acesso em: 9 de dezembro de 2019. 
AGROECOLOGIA, partilha e esperança: MST doa 12 toneladas de alimentos em Castro, Paraná. Brasil de Fato. 2020. Disponível em: <https://www. brasildefatopr.com.br/2020/08/11/agroecologia-partilha-e-esperanca-mst-doa12-toneladas-de-alimentos-em-castro-pr>. Acesso em: 17 de agosto de 2020.

ANGELO, C. Negacionistas não desistem. Observatório do Clima. 2019. Disponível em: <http://www.observatoriodoclima.eco.br/os-negacionistasbrasileiros-nao-desistem-nunca/>. Acesso em 09 de dezembro de 2019.

ANGUS, I. Antropoceno ou capitaloceno? erra o ponto. Revisão do livro. GPEA/UFMT. 2016. Disponível em: 184 <https://gpeaufmt.blogspot.com /search?q=ecosocialist+notebook>. Acesso em: 15 de agosto de 2019.

BOFF, L. Crítica ao modelo padrão de desenvolvimento sustentável. O tempo. 2012. Disponível em: <https://www.otempo.com.br/opiniao/leonardo-boff/criticaao-modelo-padrao-de-desenvolvimento-sustentavel-1.210501\#>. Acesso em 20 de agosto de 2019.

BRASIL Registra 600 mortes por covid -19 em 24 horas, maior número para um dia. CNN. Brasil. 2020. Disponível em: $<$ https://www.cnnbrasil.com.br/saude/2020/05/05/coronavirus-casos-brasil-05de-maio-de-2020>. Acesso em: 05 de maio de 2020.

BRASIL passa de cento e trinta mil mortos por COVID19; quatro estados aparecem com alta de óbitos. G1 Globo. 2020. Disponível em: $<$ https://g1.globo.com/bemestar/coronavirus/noticia/2020/09/11/casos-e-mortespor-coronavirus-no-brasil-em-11-de-setembro-segundo-consorcio-de-veiculosde-imprensa.ghtml>. Acesso em 13 de setembro de 2020.

BRASIL tem 1.354 mortes por Covid-19 nas últimas 24 horas; média móvel de óbitos é a mais baixa desde 22 de fevereiro. G1 Globo. 2021. Disponível em: <https://g1.globo.com/bemestar/coronavirus/noticia/2021/07/29/brasil-tem1354-mortes-por-covid-19-nas-ultimas-24-horas-media-movel-de-obitos-e-amais-baixa-desde-22-de-fevereiro.ghtml>. Acesso em 31 de julho de 2021.

CÂMARA Legislativa. Relator propõe recurso emergencial de $R \$ 500$ para pessoas de baixa renda. Senado Federal. 2020. Disponível em: $<$ https://www.camara.leg.br/noticias/648772-\%E2\%80\%8BRELATOR-

PROPOE-AUXILIO-EMERGENCIAL-DE-R\$-500-PARA-PESSOAS-DE-BAIXARENDA>. Acesso em: 03 de Maio de 2020.

CÉTICOS do Clima são menos de $1 \%$ da comunidade científica, diz estudo. Ecodebate. $2013 . \quad$ Disponível em: $<$ https://www.ecodebate.com.br/2013/05/28/ceticos-do-clima-sao-menos-de-1da-comunidade-cientifica-diz-estudo/>. Acesso em: 04 de Maio de 2020.

DALA-NORA, G. A água e a Cartografia do Imaginário nos climas de três territórios geográficos. 2018. (Tese de Doutorado) Universidade Federal de Mato Grosso. Instituto de Educação. Programa de pós graduação em Educação, Cuiabá. 2018. Disponível em: <http://ri.ufmt.br/bitstream/1/1889/1/TESE 2018 Giseli\%20Dalla\%20Nora.pdf>. Acesso em: 2019. 
EXONERAÇÃO do diretor do INPE. Globo. G1. 2019.Disponível em: $<$ https://g1.globo.com/natureza/noticia/2019/08/07/exoneracao-de-diretor-doinpe-e-publicada-no-diario-oficial.ghtml>. Acesso em 04 de maio de 2020.

FORTE, B. Por que o Brasil é o sétimo país mais desigual do mundo.Uol.com. 2020. Disponível em: <https://www.uol.com.br/ecoa/ultimas-noticias/2020 102/20/por-que-brasil-e-o-setimo-pais-mais-desigual-do-mundo.htm>. Acesso em: 06 de maio de 2020.

GIMENES, E. Da negação à contaminação: o trajeto de Jair Bolsonaro até o encontro com o vírus. Brasil de Fato. 2020. Disponível em: <https://www. brasildefato.com.br/2020/07/08/da-negacao-a-contaminacao-o-trajeto-de-jairbolsonaro-ate-o-encontro-com-o-virus >. Acesso em: 13 de agosto de 2020.

JACOBI, P. Educação Ambiental: o desafio da construção de um pensamento crítico, complexo e reflexivo. Educ. Pesquisa. vol.31 no.2 São Paulo May/Aug. 2005.

LAGO, I. O Jair que há em nós. Carta Maior. 2020. Disponível em: $<$ https://www.cartamaior.com.br/?/Editoria/Sociedade-e-Cultura/O-Jair-que-haem-nos/52/47388 >. Acesso em: 05 de maio de 2020.

LATOUR, B. Imaginando gestos que barrem o retorno ao consumismo e a produção insustentável pré-pandemia. Climainfo. 2020. Disponível em: $<$ https://climainfo.org.br/2020/04/02/barrar-producao-insustentavel-eonsumismo/>. Acesso em: 05 de maio de 2020.

LEMOS, V; BARRUCHO, L. Brasil chega a 150 mil mortos por COVID19, mas, número pode ser muito maior. BBC News Brasil. 2020. Disponível em: $<$ https://www.bbc.com/portuguese/brasil-54478219>. Acesso em 13 de outubro de 2020.

MEDEIROS, C. Maior produtor da América Latina, MST inicia colheita de arroz orgânico no Rio Grande do Sul. Brasil de Fato. 2020. Disponível em: $<$ https://www.brasildefato.com.br/2020/02/26/maior-produtor-da-america-latinamst-inicia-colheita-do-arroz-organico-no-rs >. Acesso em: 06 de maio de 2020.

MELO, K. Brasil registra mais de 100 mil mortes por COVID 19. Agência Brasil EBC. 2020. Disponível em: <https://agenciabrasil.ebc.com.br/saude/noticia/2020 -08/brasil-registra-mais-de-100-mil-mortes-por-covid-19>. Acesso em 15 de agosto de 2020.

MILANEZ, B. Injustiça Climática. IPEA. 2010. Disponível em: <http://repositorio.ipea.gov.br/bitstream/11058/5554/1/BRU n4 justica.pdf>.

Acesso em: 09 de dezembro de 2019.

MOORE, J. Entrevista: Antropoceno ou capitaloceno. Sinpermiso. 2018. Disponível em: <https://www.sinpermiso.info/textos/antropoceno-mas-biencapitaloceno-entrevista>. Acesso em: 15 de junho de 2019.

NEGRÃO, H. Após a Alemanha, a Noruega cancela fundo para a Amazônia. EI País. 2019. Disponível em: <https://brasil.elpais.com/brasil/2019/08/15/politica /1565898219 277747.html>. Acesso em: 04 de maio de 2020. 
NÚMERO de mortos no Brasil chegam a 6.750; Total de casos supera 96 mil. BBC. 2020. Disponível em: <https://www.bbc.com/portuguese/brasil-51713943>. Acesso em: 03 de maio de 2020.

ONU. Mudanças Climáticas. Nações Unidas. 2019. Disponível em: $<$ https://nacoesunidas.org/acao/mudanca-climatica/>. Acesso em: 03 de maio de 2020.

PBMC, Painel Brasileiro de Mudanças Climáticas. Novo estudo sobre o clima muda opinião de cientistas céticos. PBMC. 2011. Disponível Em: $<$ http://pbmc.coppe.ufri.br/index.php/en/news/278-novo-estudo-sobre-climamuda-opiniao-de-cientistas-ceticos >. Acesso em: 04 de maio de 2020.

PLATÃO, 427-347 a.C. A República / Platão. Tradução de Carlos Alberto Nunes. - 3. ed. -. Belém: EDUFPA, 2000.

PONTES, N. Produção de cloroquina coloca Bolsonaro na mira da justiça. DW. 2020. Disponível em: <https://www.dw.com/pt-br/produ\%C3\%A7\%C3\%A3o-decloroquina-coloca-bolsonaro-na-mira-da-justi\%C3\%A7a/a-54413561>. Acesso em: 17 de agosto de 2020.

PRUDENCIANO G. Washington Post considera Bolsonaro o pior líder global a lidar com o coronavírus. Estadão. 2020. Disponível em: $<$ https://politica.estadao.com.br/noticias/geral,washington-post-diz-quebolsonaro-e-o-pior-lider-global-a-lidar-com-o-coronavirus, 70003271003 > . Acesso em : 03 de Maio de 2019.

RECONHECER a importância do SUS é o primeiro passo contra a pandemia. Conasems - Conselho Nacional das Secretarias Municipais de Saúde. 2020. Disponível em: <https://www.conasems.org.br/reconhecer-a-importancia-do-suse-o-primeiro-passo-contra-a-pandemia-defendaosus/>. Acesso em: 15 de agosto de 2020.

SATO, M.; SILVA, R.; JABER, M. Educação Ambiental: tessituras de esperanças. Cuiabá: Editora Sustentável, EdUFFMT, 2018.

SATO, M. COVID-19 e o vírus que avança pela periferia urbana. In: Os Condenados da Pandemia. Livro eletrônico. Michèle Sato (org.) e vários autores. 1aㅡ Ed. Cuiabá: Sustentável. 2020. cap.12, p.99-101.Disponível em: $<$ https://onedrive.live.com/?authkey=\%21AK6jz0W42U\%2DY8dE\&cid=6F738C 9 CF42A30B0\&id=6F738C9CF42A30B0\%2155024\&parld=6F738C9CF42A30B $0 \% 2117287 \& 0=$ OneUp $>$. Acesso em 17 de agosto de 2020.

TAMAIO, I. Educação Ambiental e Mudanças Climáticas. Diálogo necessário em um mundo em Transição. Brasília: Ministério do Meio Ambiente, 2013.

TEMÓTEO, A.; MILITÃO, E. Guedes afirma que governo vai pagar $\mathrm{R} \$ 200$ para trabalhador informal. Economia UOL. 2020. Disponível em: $<$ https://economia.uol.com.br/noticias/redacao/2020/03/18/guedes-afirma-quegoverno-vai-pagar-r-200-para-trabalhador-informal.htm>. Acesso em: 03 de maio de 2020. 